\title{
A Metrópole é Aqui: Redes de Abastecimento e o Porto do Rio de Janeiro no Século XIX
}

\section{The Metropolis is Here: Supply Networks and the Port of Rio de Janeiro in the Nineteenth Century}

\author{
Patrícia Gomes da Silveira ${ }^{i}$ \\ Universidade Federal do Rio de Janeiro \\ Rio de Janeiro, Brasil
}

\begin{abstract}
Resumo: Nesse texto iremos discutir os fatores e processos envolvidos na formação das redes de abastecimento de gêneros alimentícios no século XIX, estabelecendo como eixo principal as interações sócio-espaciais que o porto do Rio de Janeiro mantinha com os portos costeiros do Brasil. Ao estudar as redes de abastecimento no século XIX não intentamos reter do passado aquilo que é essencial para a compreensão do presente, e sim entender qual a lógica e as práticas sócio-espaciais envolvidas na formação dessa rede. A fonte primária consultada foi o Códice de Embarcações, disponibilizada pelo Arquivo Geral da Cidade do Rio de Janeiro (AGCRJ), que retrata o comércio de cabotagem entre 1795-1828. A rede em tela foi marcada por uma interconexão instável entre os lugares que a formavam. Onde as redes existem elas são vetores de diferenciação.Uma pluralidade de pontos estava articulada por inúmeras ramificações que partiam de pontos privilegiados do território, em especial do Centro-Sul.
\end{abstract}

Palavras-chave: Redes, Abastecimento, Porto do Rio de Janeiro, Geografia Histórica

\begin{abstract}
This presents factors and processes involved in the formation of networks for supplying foodstuffs in colonial Brazil, in which the port of Rio de Janeiro acted as the main hub of socio-spatial relationships with other coastal ports of the country. This study of the food supply network of the colonial period does not merely retrieve from the past what is essential for understanding the present, but instead tries to understand the original logic and socio-spatial practices involved in the rise of the network. The primary source used is the Codices of Shipping for the period of 1795-1828, which was researched in the General Archive of the City of Rio de Janeiro (AGCRJ). The supply of food in the period of study was marked by unstable interconnections between the ports. Where networks existed they took the form of differentiated vectors and a plurality of points was articulated by numerous branches stemming out from privileged territorial points, especially in the Central-South.
\end{abstract}

Keywords: Networks, Food supply, the Port of Rio de Janeiro, Historical Geography

\section{Introdução}

Durante muito tempo a história econômica interpretou a economia colonial como uma sucessão dos grandes ciclos (açúcar, ouro, café), não valorizando as lógicas e as

\footnotetext{
' Mestranda do Programa de Pós-Graduação em Geografia, patyviagem@gmail.com
} 
Silveira, P. G.

práticas sócioeconômicas cotidianas estabelecidas no Brasil colônia (PRADO JUNIOR, ([1945] 1978) e FURTADO ([1959] 1989).

O mercado doméstico e a economia de subsistência, segundo Lenharo (1979), eram entendidos como complementares e subordinados à economia exportadora, esta sendo vista como a razão de ser da economia colonial.

Nas palavras de Braudel (1996) as colônias só existiam para sustentar a riqueza, o poder e o prestígio das metrópoles. No relato de um soldado inglês que regressava de uma fracassada missão diplomática na China, é possível entender a importância econômica que o Brasil representava para Portugal, bem como a diversidade de produtos aqui explorados: "O Rio de Janeiro é a feitoria mais importante que Portugal possui. Ela produz açúcar, tabaco e algodão. Dela retira-se também couro e excelentes drogas para a medicina e para a manufatura; sem falar do ouro, da prata e dos diamantes" (FRANÇA, 2000, p. 253).

Alguns autores, como Lenharo (1979), Fragoso (1998) e Florentino (2010), entretanto, passaram a contestar a validade desses modelos explicativos que supervalorizavam a economia exportadora em detrimento do reconhecimento de que existia um mercado interno, com uma lógica própria de organização e formado por espaços distantes das core áreas dos grandes ciclos econômicos.

Nesse sentido, o objetivo deste trabalho consiste na discussão sobre os fatores e processos envolvidos na formação das redes de abastecimento de gêneros alimentícios no período colonial, estabelecendo como eixo principal as relações sócioeconômicas que os lugares, especificamente os portos costeiros, estabeleciam entre si, a partir dos fluxos econômicos do comércio de cabotagem.

A discussão sobre a formação dessa rede não se encerra nos portos ou no setor marítimo, visto que, parte da produção escoada pelos portos brasileiros era proveniente dos "sertões" do Brasil. É fundamental desvendar as vias de comunicação que conectavam o litoral e o sertão, seriam os caminhos terrestres? Rios? Baías? Para Fréderic Mauro (1966) as economias do interior do Brasil estavam indiretamente vinculadas aos ciclos econômicos, permitindo a sobrevivência da economia marítima e das cidades litorâneas.

Na economia-mundo de Braudel (1996), as cidades-mundos são o centro da logística e dos negócios, porém não são eternas. Quando ocorre a substituição de uma cidade-mundo, isso revela a fragilidade do sistema anterior e a força do que vai se estabelecer. No caso do Brasil, Salvador teve seu apogeu como uma das principais cidades da América, entretanto, novos eventos no sistema econômico português, contribuíram para que o Rio de Janeiro se tornasse um ponto de convergência de diversos mercados regionais e internacionais a partir de meados do século XVIII.

Entre 1796 e 1811, o porto do Rio foi responsável por 38\% das exportações e por $34 \%$ das importações, já Salvador foi responsável, respectivamente, por 27\% e $26 \%$. Esses números ilustram como o Rio de Janeiro tornou-se um espaço mercantil importante no Império português. 


\section{Rio de Janeiro: uma Entrepôt-city do Brasil Colonial}

O título da dissertação evoca a crescente importância que a cidade do Rio de Janeiro assumiu no Império Português. Primeiro, por ter se tornado capital do Brasil em 1763, deslocando o eixo econômico e administrativo do Nordeste para o Sudeste, e em segundo, por a partir de 1808 ter sido a residência da Família Real, tornando-se assim a capital do Império luso.

Na última década do século XVII o pacato cotidiano da cidade fluminense foi bruscamente alterado pela notícia de descobrimento de metais preciosos nas Gerais. A partir desse momento o Rio de Janeiro nunca mais seria o mesmo. Instituído como o principal porto exportador dos metais preciosos para a metrópole e importador dos escravos oriundos da África, a cidade deixava para trás seu papel secundário na colônia e caminhava em direção a uma cidade articulada com distintos pontos do território e com uma paisagem urbana em transformação (ABREU, 2000).

Estima-se que o porto do Rio de Janeiro tenha recebido no mínimo 50\% dos escravos oriundos da África, durante o século XVIII. Em 1789, a capitania do Rio de Janeiro possuía 82.448 escravos, em 1823, esse número salta para aproximadamente 150.000 escravos (FLORENTINO, 2010).

No auge da mineração, a demanda por alimentos era crescente e para abastecer a população livre e escrava das Gerais, rotas terrestres eram criadas a partir de vários pontos do Brasil, em especial partindo do Rio de Janeiro, São Paulo e Bahia. Os caminhos terrestres criados nos territórios auríferos funcionavam também como base normativa e material que iria servir como alicerce para a nova configuração territorial do Brasil (STRAFORINI, 2007).

A partir desse período, a Baía de Guanabara passou a ser intensamente "povoada" por embarcações de todos os tipos - sumacas, lanchas, canoas, bergantins - que tinham os mais variados destinos na colônia (ABREU, 2010). No entorno da Baía existiam pequenos portos que transportavam gêneros alimentícios do recôncavo da Guanabara para o abastecimento do Rio de Janeiro e portos, como o de Guaratiba, que constituía uma passagem importante do ouro que vinha pelo Caminho Velho para o Rio de Janeiro.

O abastecimento da cidade do Rio de Janeiro provinha de freguesias, como: Itaboraí, Itaguaí, Magé, Jacutinga, Parati e Campos dos Goytacases, que enviavam pequenas embarcações para a cidade, contendo, principalmente: arroz, milho, feijão, farinha e em alguns casos: madeira, tabuado e lenha. Em 1778, o porto das Caixas possuía 14 barcos com mantimentos que seriam enviados ao Rio de Janeiro e o porto da Estrela possuía 17 embarcações (LAVRADIO, 1779).

Para Caio Prado Jr. ([1945] 1978), a grande propriedade teve um papel pouco relevante no abastecimento dos centros urbanos, sendo os grandes abastecedores as pequenas e médias propriedades situadas na periferia imediata desses centros.

Diante da crescente demanda por alimentos, sabe-se que essa hinterlândia não conseguia abastecer o entreposto do Rio de Janeiro, sendo necessário que outras localidades fossem inseridas no comércio de cabotagem: 
Silveira, P. G.

[...] somente o Rio de Janeiro teria sido exceção a essa regra, porque contou com o auxílio das regiões costeiras que formavam o litoral sul da Colônia (a antiga capitania de São Vicente e no século XVIII, Santa Catarina e Rio Grande do Sul), que se especializaram na produção de alimentos por terem solos pobres, não adequados à lavoura canavieira. (ABREU, 2010, p. 64).

Outro evento inesperado marcou novamente a vida da cidade em todos os sentidos- econômico, político, cultural, social. A vinda da comitiva real para a colônia impôs ao Rio de Janeiro uma nova classe social que passou a exigir mudanças nas condições materiais da cidade para atender aos seus anseios, bem como para o desempenho de atividades econômicas (ABREU, [1987] 2006).

Ao discutir as noções de centro e periferia no contexto do Brasil colonial, Russel-Wood (1998) reconheceu que a chegada da corte, fez do Brasil o cenário central e a cidade do Rio de Janeiro, outrora tida com periferia, poderia ser considerada como centro da colônia e do Império. Essa cidade que vista de longe maravilhava os estrangeiros, com um olhar mais apurado, revelava um cenário um pouco invertido: era a metrópole improvável do Brasil.

Para Bernardes (1961) a partir de meados do século XIX, o Rio de Janeiro inicia sua caminhada como principal centro político do Brasil e polo econômico, através da função portuária e financeira e posteriormente pela função industrial e administrativa. A centralidade do Rio de Janeiro não se impôs apenas na sua posição geopolítica na América, mas em todo o Império ultramarino português.

Com o desenvolvimento dessas funções, o Rio de Janeiro passou a atrair um elevado contingente populacional. Segundo Marcondes (2001), a população da cidade em 1799 era de aproximadamente 43 mil pessoas, em 1808 de 60 mil e em 1819 de 90 mil pessoas. No caso da província do Rio de Janeiro, a população passou de 168.849 habitantes em 1789 para 591.000 em 1830, tendo um crescimento de $250 \%$.

No decorrer do século XIX, a cidade passou por modificações substanciais em sua aparência e em seu conteúdo. As freguesias centrais, como Candelária e São José, eram o símbolo de algumas modernidades introduzidas no Brasil, entretanto também acumulavam as contradições da cidade do Rio de Janeiro, que só seriam parcialmente resolvidas com as reformas do período Passos (1902-1906).

\section{Das Sumacas e Bergantins: as Redes de Abastecimento e o Porto do Rio de Janeiro}

A rede deve refletir uma estrutura de interações, entre indivíduos, firmas, serviços, produtos, entre outros. Segundo Dias (1995) as redes técnicas e os equipamentos de solidariedade urbana, são os vetores principais da formação de uma rede urbana e da integração territorial, sendo as redes de transporte e de comunicações agentes importantes desse processo.

As redes de circulação marítima ou terrestre que percorriam o território tinham nas cidades portuárias a marca do poder e da riqueza que as mesmas passaram a polarizar. Isso corrobora com a afirmação de Galvão ([1966] 2009) de que a distribuição da rede 
de transportes no território brasileiro é um indício do desenvolvimento econômico de certos lugares.

A formação do sistema de transportes no Brasil colônia está associada aos imperativos da natureza. Entretanto, não podemos tomar o desenvolvimento da rede de transportes somente pelas condições físicas. Um sistema de circulação é um instrumento criado, fruto de interesses e estratégias dos atores que o produzem e reproduzem. O desenho desta rede era também uma resposta às injunções históricas e econômicas. Em decorrência dos interesses econômicos que guiaram a ocupação do Brasil, pautada principalmente no litoral, o que na verdade existia era um arquipélago de portos, cada um rodeado por sua zona agrícola e fortemente conectado à metrópole (PRADO JUNIOR, [1945] 1978).

No período colonial, o transporte aquaviário (fluvial/marítimo) era fundamental para articular os lugares na escala regional e internacional. A navegação fluvial era muito expressiva no Brasil, sendo a principal via escolhida para a circulação de pessoas e mercadorias. Nas palavras de Braudel (1990, p. 384): "Por estes caminhos e canais, barcos, barcaças impelidos à vara dirigem-se continuamente para a grande cidade. Mas por toda a parte se utiliza qualquer pequeno curso d'água".

Para se chegar as Minas partindo da Bahia, a principal rota era através dos rios que cortavam os sertões do Brasil, tendo como uma espinha dorsal desse sistema de circulação o rio São Francisco e seus afluentes, como o rio das Velhas, Verde e Paracatu (PRADO JUNIOR, [1945] 1978).

Em relação aos tipos de embarcações, havia uma grande variedade e cada uma tinha sua especificidade quanto à tonelagem, tamanho, capacidade de passageiros, duração da viagem, entre outros atributos.

No caso das lanchas e sumacas, eram mais indicadas para viagens de curto a médio prazo, ao contrário do bergantim, indicado para viagens longas, o que podemos confirmar pelos dados sobre o comércio do Rio de Janeiro com o porto de Rio Grande. A tabela abaixo apresenta a tonelagem média das principais embarcações que circulavam pelo Brasil, tanto no transporte de cabotagem como no trans-oceânico (Tabela 1).

Tabela 1: Embarcações e a tonelagem média.

\begin{tabular}{cc}
\hline Tipo de embarcação & Tonelagem \\
Bergantim & $130-180$ \\
Brigue & 182 \\
Corveta & $800-1000$ \\
Escuna & 140 \\
Fragata & $400-900$ \\
Galera & 254 \\
late & 47 \\
Patacho & 127 \\
Sumaca & $80-114$ \\
\hline
\end{tabular}

Fonte: SANTOS, 1993. 
Silveira, P. G.

Em relação à circulação de mercadorias na cidade do Rio de Janeiro, a densa rede fluvial que a circunda teve papel primordial na articulação entre a cidade e seu recôncavo. Desde o século XVII, o curso dos rios Pilar, Meriti, Iguaçu e Sarapuí, já eram marcados pela "paisagem do açúcar". O transporte das caixas de açúcar até o porto do Rio de Janeiro era realizado através dos rios tributários da Baía de Guanabara.

Podemos ver na figura 1 dois "portos das caixas" mais importantes do Recôncavo- Porto da Estrela e Porto das Caixas. Esses portos tiveram grande importância para o transporte fluvial, bem como ponto de partida para os caminhos que levavam as minas, como o Caminho Novo de Garcia Rodrigues e o Caminho da Serra (ABREU, 2010).

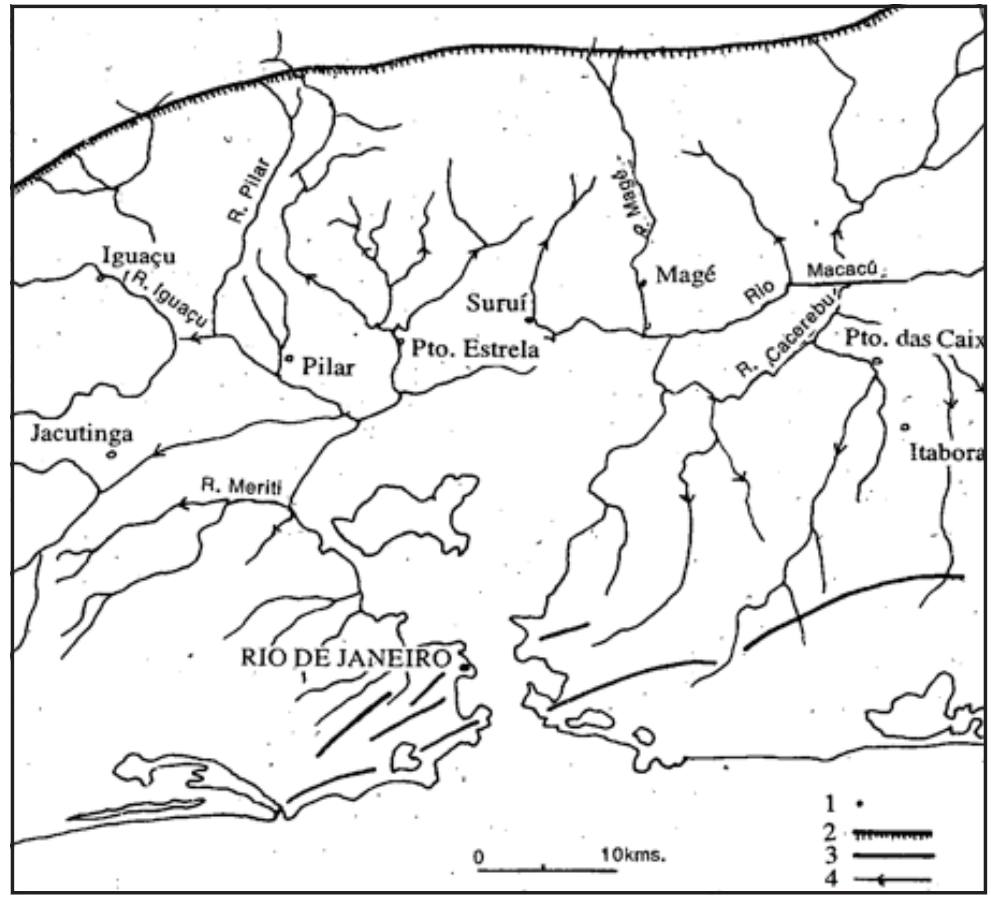

Figura 1 - Rio de Janeiro e as vias fluviais do Recôncavo da Guanabara. Fonte: BERNARDES, 1990.

Entretanto, segundo Abreu (2010) a cultura canavieira no Recôncavo da Guanabara não produziu nesse lugar a paisagem de grandes e contínuos canaviais, como era observado na época na Zona da Mata Pernambucana e no Recôncavo Baiano.

A cidade (Rio de Janeiro) era o mercado principal dessa região e muitos produtores dessa hinterlândia podiam facilmente viajar até a cidade, para poder vender sua produção. (...) Grande parte da produção da pequena hinterlân- 
dia era transportada parcialmente ou totalmente pelos canais da região [...], em geral podemos dizer que essa área era definida pela bacia de drenagem da bacia da Guanabara (BROWN, 1986, p.148).

No século XIX, os portos marítimos e fluviais do Rio de Janeiro passaram a ser procurados pelos cafeicultores da Serra e do Vale do Paraíba. Podemos destacar os portos de Angra dos Reis, Ariró, Mangaratiba, Magé, Macaé, Parati e Porto das Caixas. Os caminhos que articulavam litoral e sertão partiam principalmente de Resende, Barra Mansa, Rio Claro e São João Marcos, terminando muita das vezes no litoral, nos portos de Angra dos Reis, Mambucaba e Mangaratiba (QUINTIERE, 1951).

A procura por determinados portos gerava disputa entre os mesmos, em especial entre os da Baía da Ilha Grande. Onde as redes existem elas são vetores de diferenciação entre os lugares, dessa forma, o que na verdade as redes criam, não são espaços duais, e sim desigualdades territoriais (PIRES DO RIO, 2009). Essa concorrência reforça a estrutura de diferenciação dos lugares que formam uma rede, fazendo com que os mesmos tenham uma posição estratégica mais ou menos duradoura. Além disso, os nós que a compõem podem fazer parte, simultaneamente, de diversas redes, tendo em cada rede uma posição diferenciada, visto que a seletividade espacial é um elemento importante para a compreensão do arranjo da rede no território.

Para Santos ([1996] 2006), as redes integram e desintegram, destroem velhos recortes espaciais e cria novos, logo, esse caráter instável, móvel e inacabado, ilumina um aspecto importante na configuração das redes territoriais.

Para entender a dimensão espacial da rede de abastecimento em tela, cruzamos os dados sobre a origem das embarcações que chegaram ao porto do Rio de Janeiro e seu quantitativo. A construção dos cartogramas levou em consideração dados provenientes da Revista do Instituto Histórico Geográfico Brasileiro (RIHGB) e dos Códices de Embarcações-AGCRJ.

Para completar as informações do final do século XVIII, uma edição do RIHGB apresenta o quantitativo, a origem e os produtos trazidos por embarcações que aportavam no porto do Rio de Janeiro, sendo assim temos dados para 1791, 1793 e 1799. Em relação à 1802, sua escolha é justificada por ser uma data anterior a chegada da família Real e a abertura dos portos; 1813 pode nos apresentar uma conjuntura pós-abertura dos portos e 1819 é um dos anos finais de nosso levantamento, o que irá permitir avaliar a evolução do comércio de cabotagem, representado nos cartogramas nas figuras 2,3,4,5 e 6 . 
Silveira, P. G.

\section{Origem das embarcações no porto do Rio de Janeiro - 1791}

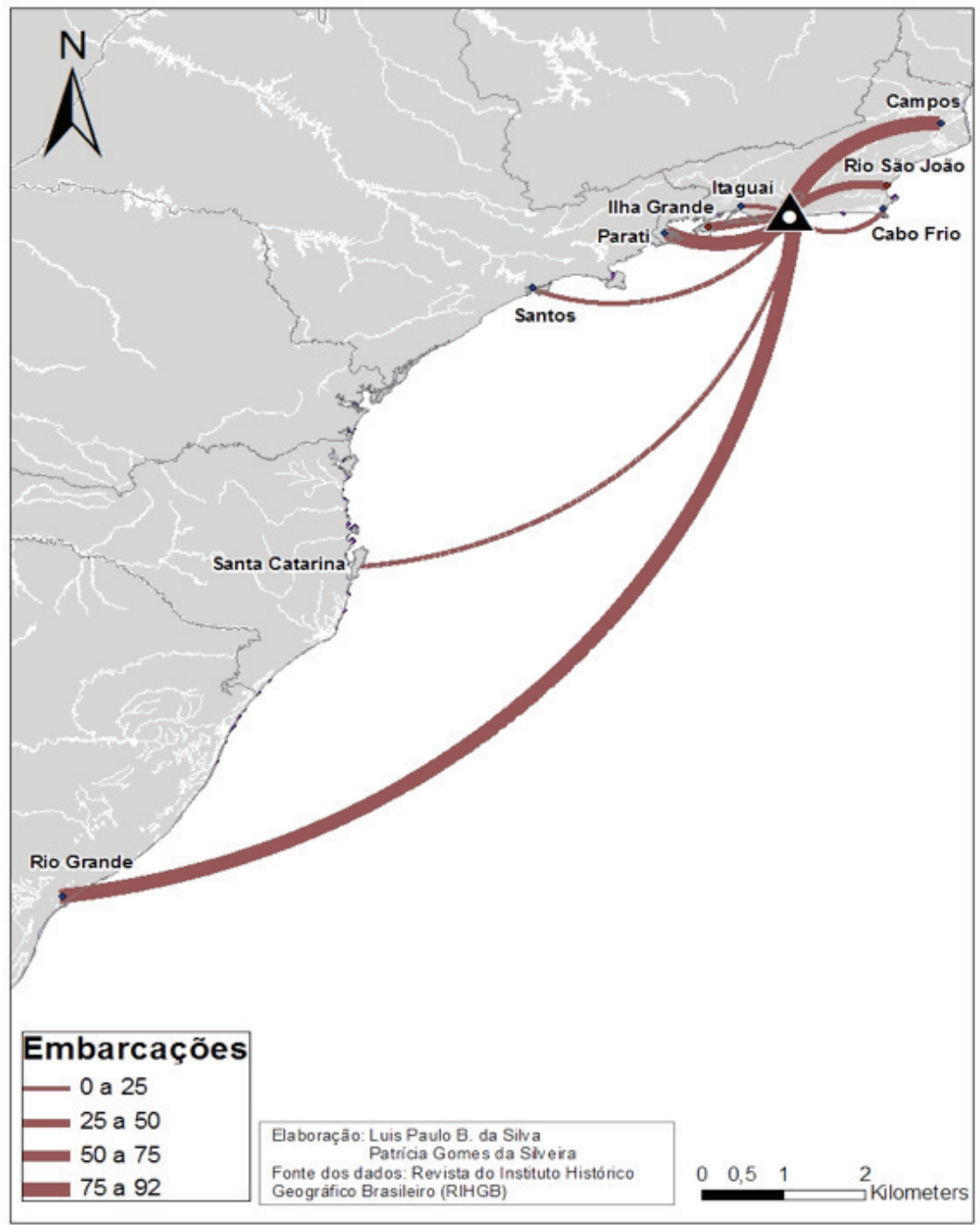

Figura 2 - Quantidade de embarcações que aportaram no porto do Rio de Janeiro e sua respectiva origem, 1791 .

Fonte: RIHGB, 1965, vol. 266. 
A Metrópole é Aqui: redes de abastecimento e o porto do Rio de Janeiro no século XIX

Origem das embarcações no porto do Rio de Janeiro - 1793

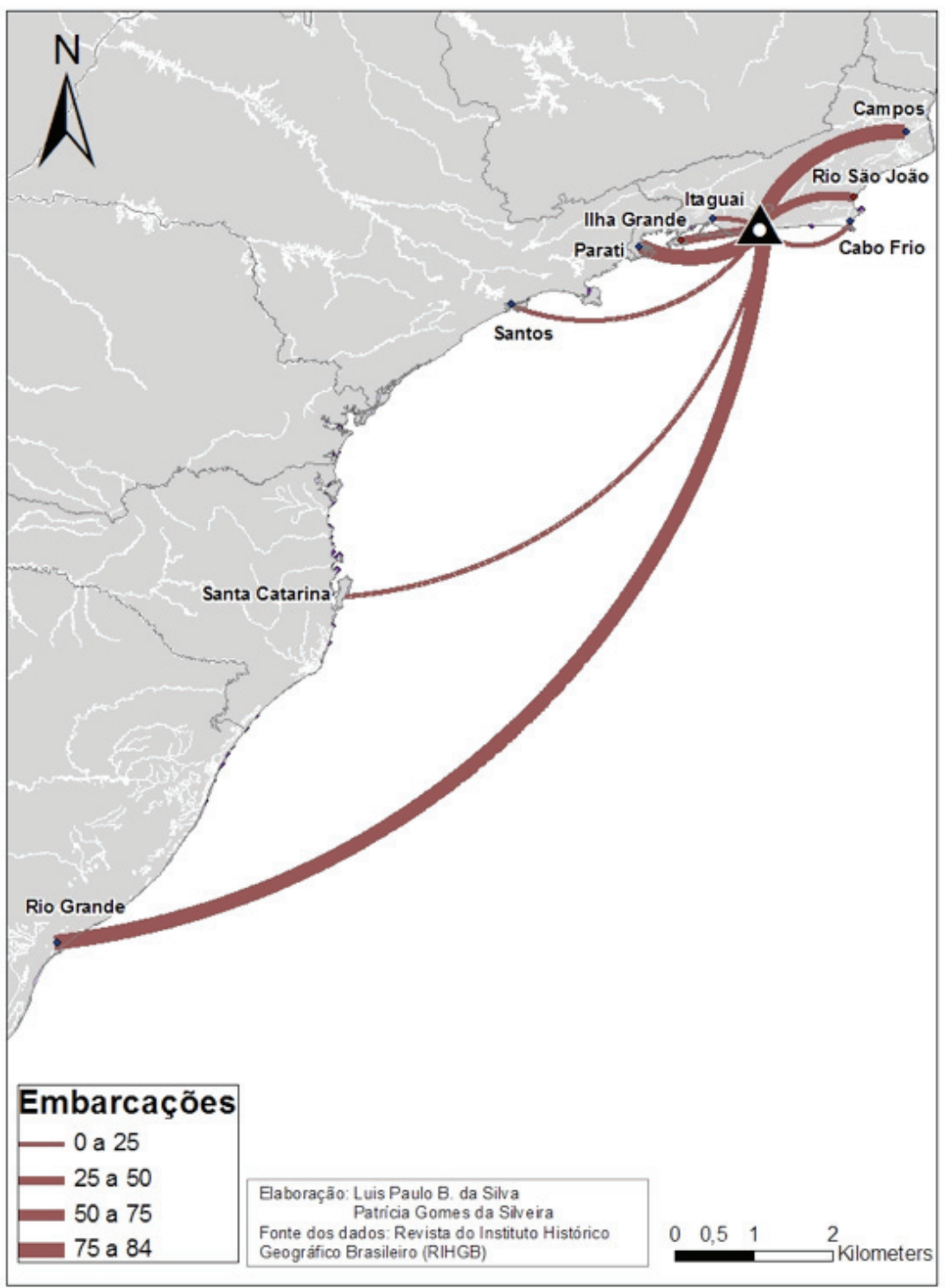

Figura 3 - Quantidade de embarcações que aportaram no porto do Rio de Janeiro e sua respectiva origem, 1793 .

Fonte: RIHGB- 1965, vol. 266. 
Silveira, P. G.

\section{Origem das embarcações no porto do Rio de Janeiro - 1802}

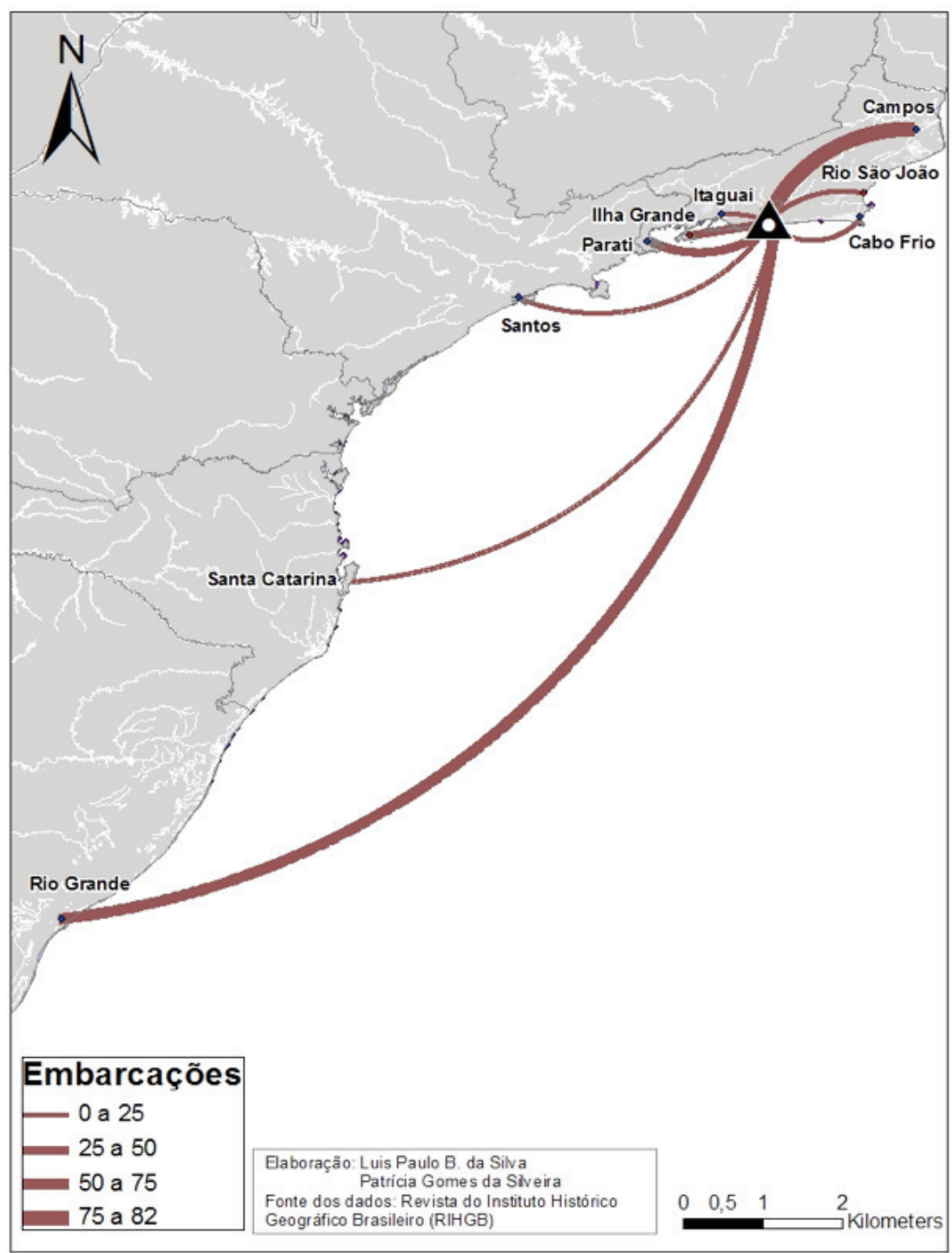

Figura 4 - Quantidade de embarcações que aportaram no porto do Rio de Janeiro e sua respectiva origem, 1802 .

Fonte: Códice de Embarcações-AGCRJ. 
A Metrópole é Aqui: redes de abastecimento e o porto do Rio de Janeiro no século XIX

\section{Origem das embarcações no porto do Rio de Janeiro - 1813}

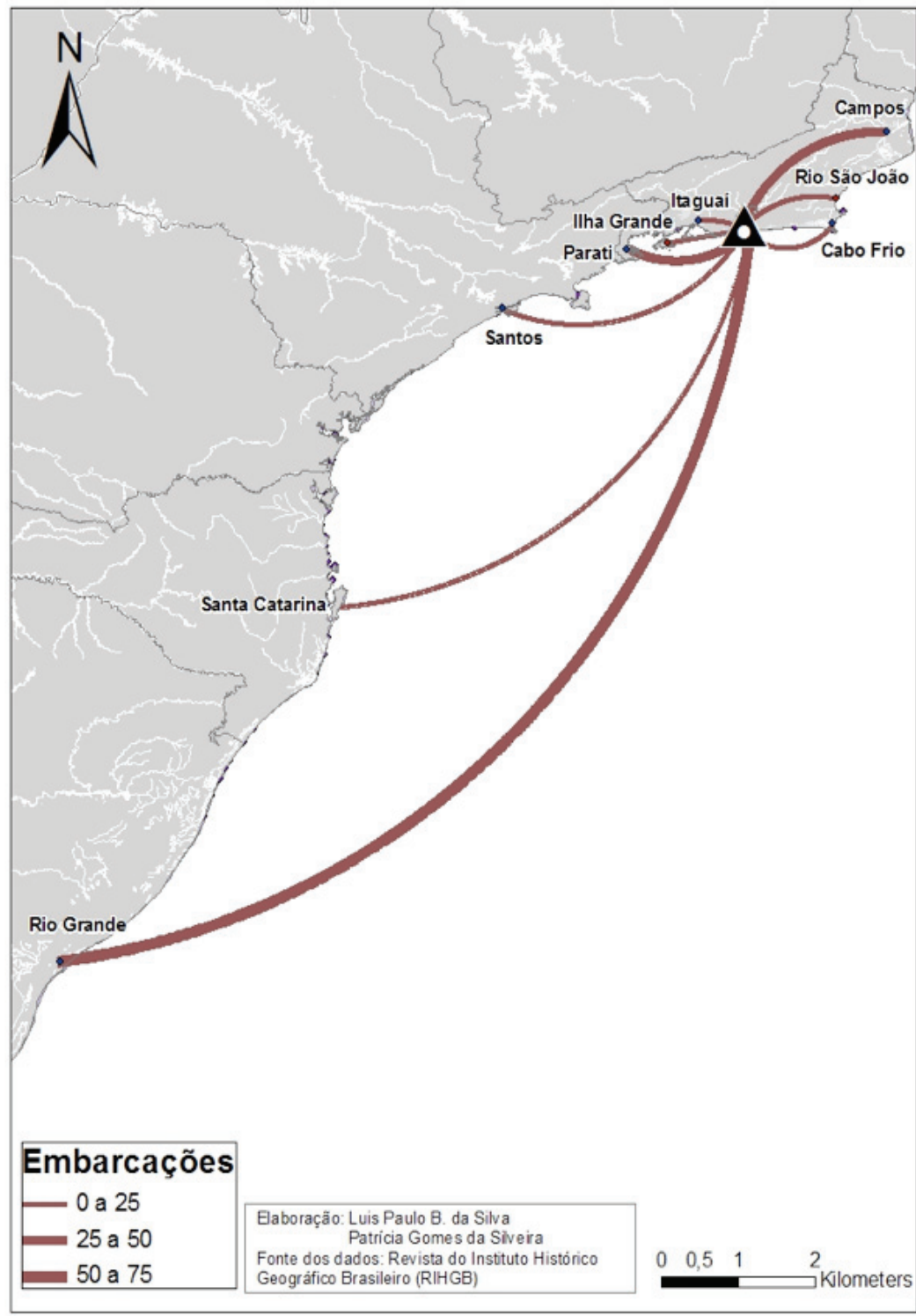

Figura 5 - Quantidade de embarcações que aportaram no porto do Rio de Janeiro e sua respectiva origem, 1813 .

Fonte: Códice de Embarcações-AGCRJ. 


\section{Origem das embarcações no porto do Rio de Janeiro - 1819}

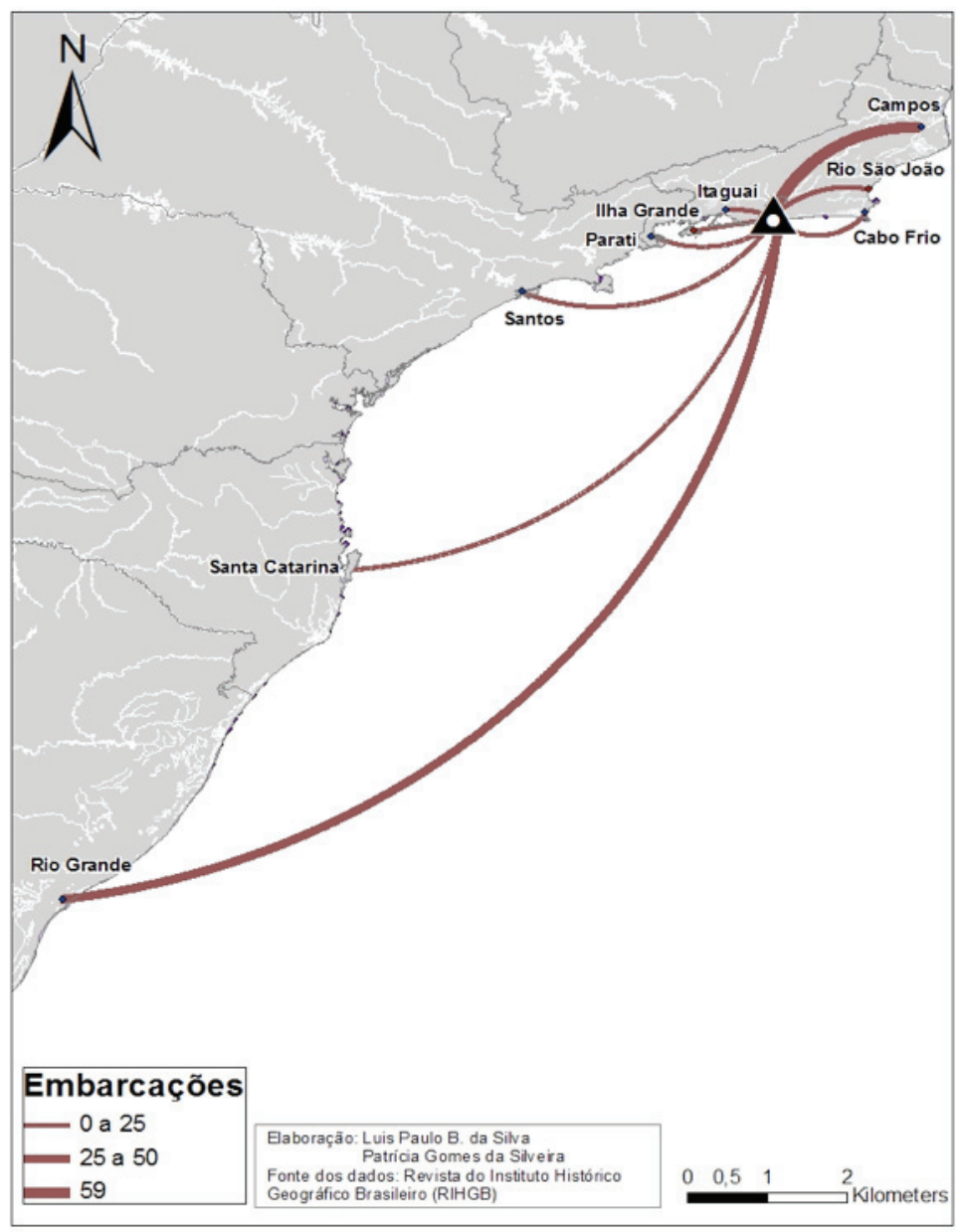

Figura 6 - Quantidade de embarcações que aportaram no porto do Rio de Janeiro e sua respectiva origem, 1819.

Fonte: Códice de Embarcações-AGCRJ.

O recorte espacial dos cartogramas põe em relevo as atuas regiões Sul-Sudeste, pois conforme afirma Marcondes (2001) as principais interações espaciais na circulação regional de alimentos ocorriam nessa escala. Percebemos uma forte conexão entre o Rio de Janeiro e as "capitanias de baixo", em especial com as cidades dos atuais estados do Rio Grande do Sul e São Paulo, por outro lado a interação com as capitanias do Nordeste era pouco significativa no comércio de cabotagem.

O Rio de Janeiro aparece como o centro da rede de abastecimento de gêneros alimentícios. Essa afirmação nos remete à classificação de E.A.J. Johnson sobre as cidades que compõem a rede dendrítica: "Os bens destinados à exportação e uma variedade de produtos 
para a população urbana, são cultivados em um "near rural market", são processados nas cidades estratégicas e depois seguem para as cidades portuárias" (JOHNSON, 1970, p.85).

Observando os cartogramas acima é certo que algumas tendências quanto às interações entre os portos podem ser notadas. Os cartogramas de 1791 e 1793 têm em comum a elevada participação de Rio Grande, Campos e Parati, que enviaram uma média de 80 embarcações para o Rio de Janeiro nos anos em tela.

Essas cidades como os principais nós da rede de abastecimento, pois o número de embarcações provenientes desses locais apresenta os maiores valores durante o período em tela, com exceção do ano de 1813, em que há uma redução nos fluxos entre o Rio de Janeiro e essas cidades.

Ao nos defrontarmos com os cartogramas acima, percebemos como um porto distante, como o de Rio Grande (RS), possuía uma forte interação espacial com a cidade-porto do Rio de Janeiro, nesse caso, o papel da distância deve ser relativizado. Entre 1799 e 1822, a exportação de charque do Rio Grande para o Rio de Janeiro cresceu 249\% (FRAGOSO e FLORENTINO, 1993). O Rio de Janeiro servia como uma entrepôt-city do comércio atlântico, já que os couros de Rio Grande eram exportados pelo porto carioca.

Ao tratar sobre o efeito da distância, Pumain e Saint-Julien (2010) reconhecem que as interações espaciais são influenciadas em grande medida pela distância, de forma que à medida que ela aumenta, as interações espaciais são menos intensas e frequentes. Para Rio Grande, verificamos o contrário. Nesse caso, as autoras reconhecem que caso um lugar tenha se especializado em algum produto, isso pode contribuir para individualizar essa unidade espacial, bem como para incrementar as interações espaciais entre o lugar especializado e os outros espaços que buscam complementaridade.

Com relação à Paraty, ela se destacou como importante porto diante do volume de produtos que enviava para o Rio de Janeiro, pois segundo Brown (1986) a cidade era responsável por enviar produtos oriundos de cidades como Cunha, Guaratinguetá e do sul de Minas. Desde o final do século XVII, Parati era um importante ponto de penetração em direção aos sertões, o que lhe garantia certa centralidade em relação aos outros portos que lhe circundavam, como os de Angra e Mambucaba.

O Caminho Velho, que partia do Rio de Janeiro em direção ao sul de Minas, possuía trecho terrestre e marítimo, pois passava por Santa Cruz, Sepetiba, ilhas da baía de Angra dos Reis, Parati, Cunha, Guaratinguetá, garganta do Embaú e daí alcançava Minas Gerais. Porém, como o trecho marítimo do Caminho Velho era alvo de corsários, Garcia Rodrigues optou por não "desenhar" o Caminho Novo pelo trecho Sepetiba-Parati e sim seguir pela Serra dos Órgãos até chegar a Ouro Preto (QUINTIERE, 1951).

Qualquer caminho criado significa um progresso, condição para outros progressos. A abertura do Caminho Novo, que originalmente era uma rota indígena, foi apropriada no século XVIII pelos portugueses e paulistas. Dessa forma, seu traçado pelo território não é em si uma novidade.

A necessidade de abastecimento das minas contribuiu para as conexões de solidariedade econômica, capazes de induzir a integração regional (DIAS, 1995), nesse sentido para Straforini (2007) o Caminho Novo transformaria os sertões auríferos em territórios auríferos. Como parte desses caminhos quase sempre se deve às experiências indígenas (BRAUDEL, 1996), sua apropriação e seu uso, se devem ao colonizador, imbuído do desejo de solidariedade econômica e territorial. 
Silveira, P. G.

Os portos de Itaguaí e Guaratiba apresentam um reduzido fluxo de embarcações com o porto do Rio, entretanto isso não reduz sua importância no abastecimento da cidade. Itaguaí, por exemplo, era um importante fornecedor de arroz, em conjunto com Paranaguá (PR) e Vitória (ES), além disso, também exportava a produção de localidades próximas, como Marapicu.

Se algum comportamento caracteriza as interações entre o porto do Rio de Janeiro e os portos mapeados, são as intensas interações sócio-espaciais estabelecidas entre o Rio de Janeiro e as cidades de Rio Grande, Campos e Parati, que concentravam a produção de sua hinterlândia e a embarcavam para a "urbe carioca".

Concordamos com Brown (1986) ao afirmar que a "hinterlândia interior" do Rio de Janeiro era constituída por: capitanias de Minas Gerais, Mato Grosso, sul da capitania de Goiás e o interior das capitanias de São Paulo e Rio Grande do Sul. Entretanto, qual seria o sentido de interior tomado pela autora?

Encontrar o Brasil nos seus limites internos nos séculos XVI e XVII era superar um obstáculo que o termo "interior" impunha enquanto representação. (...) o pensamento entre o conhecido (entendido como o que estava perto ou na própria faixa litorânea) e o desconhecido (entendido como o que estava longe ou no interior). Para Geiger (2005:165), tais conceitos "não se resumem a uma distância física, mas assumem um significado político (STRAFORINI, 2007, p.73).

Os dados aqui utilizados nos mostram o quão complexo era a circulação de gêneros alimentícios no período em tela, visto que a mesma se espraiava pelos sertões do Brasil, suprindo-os não apenas com manufaturados e escravos do setor marítimo, mas adicionalmente, com alimentos destinados ao abastecimento das cidades que nasceram a partir da mineração.

O centro se distingue da periferia pela sua capacidade de concentrar elementos que exprimem centralidade, sejam eles, econômicos, culturais, políticos, ou pela sua capacidade de exercer atração ou dominação sobre outros espaços (PUMAIN E SAINT-JULIEN, 2010). Os papéis que os nós de uma rede exercem, não são apenas como lugares de conexão, mas também como lugares de poder (RAFFESTIN, 1980), condição que ficou mais evidente na cidade do Rio de Janeiro após ter se tornado capital do império português em 1808. Esse evento veio reforçar o papel de centro que essa antiga periferia passou a assumir na escala do império ultramarino português.

\section{Considerações Finais}

Passado, presente e futuro não são categorias que definem uma ciência social. A ditadura do presente que vigorou por muito tempo na geografia, hoje já não faz mais sentido, tendo o passado sua própria importância, não sendo mais preciso ser estendido até o presente.

As interações espaciais são marcadas por fluxos assimétricos que percorrem as redes, reforçando a atratividade que cada lugar oferece. Instável no tempo, móvel e inacabada, são os elementos que põe em relevo as características das redes e que de fato contribuem para sua compreensão e seu desenho no território. 
A rede de abastecimento de gêneros alimentícios foi marcada por uma interconexão instável entre os lugares que a formavam. Uma pluralidade de pontos, nesse caso representado pelos portos e/ou pelas cidades no sertão do Brasil, estavam articuladas por inúmeras ramificações que partiam de lugares privilegiados do território, responsáveis por estreitar os laços entre os subespaços econômicos da colônia, sustentando o argumento da crescente importância que o mercado interno assumiu para a expansão econômica da época. Estima-se que em torno de $85 \%$ da produção brasileira no inicio do século XIX era consumida na própria colônia.

A mineração foi capaz de oferecer maior fluidez e articulação entre as regiões mineradoras e o litoral, desse modo, os sertões passaram a integrar a complexa rede de abastecimento.

Os antigos sertões auríferos também desenvolveram atividades agrícolas, como foi o caso da região de Baependi, Airuoca e Carrancas, que se especializaram na produção de tabaco. As interações entre o sertão e o porto do Rio envolviam a circulação terrestre do fumo até Paraty, que após fazer escala no Rio de Janeiro seguia para seu principal mercado consumidor: Rio da Prata. Parafraseando Milton Santos, as redes seriam incompreensíveis se apenas as estudássemos a partir de manifestações locais.

O mercado ultramarino formado por Portugal e seus domínios no além-mar era complexo e formado por uma intricada rede de negócios que se espraiavam pelo mare lusitano. No caso do Brasil, a partir de meados do século XVIII, o Rio de Janeiro se tornou um dos principais nós das redes que percorriam o território. O porto do Rio era um dos atores principais dessa encruzilhada de redes de comércio que se espraiavam pelo Atlântico e pelas terras brasileiras.

\section{Referências Bibliográficas}

ABREU, M.A. Construindo uma Geografia do Passado: Rio de Janeiro, cidade portuária, século XVII. In: GEOUSP-Espaço e Tempo. São Paulo, n7, 2000. p. 13-25.

ABREU, M.A. Geografia Histórica do Rio de Janeiro (1502-1700). Rio de Janeiro, Andrea JaKobsson Estúdio, 2v, 2010.

BERNARDES, L.M.C. Expansão do Espaço Urbano no Rio de Janeiro. Revista Brasileira de Geografia. Jul-set, 1961.

BERNARDES, L.M.C. Importância da Posição como Fator do Desenvolvimento do Rio de Janeiro. In: BERNARDES, L.M.C.; SOARES, M.T.S. (Orgs.). Rio de Janeiro: cidade e região. Rio de Janeiro: Secretaria Municipal de Cultura, 1990. p. 21-38.

BRAUDEL, F. Civilização Material, Economia e Capitalismo- séculos XV-XVIII - O Tempo do Mundo. São Paulo: Martins Fontes, $3^{\circ}$ volume, 1996.

BROWN, L.V. Internal Commerce in a Colonial Economy: Rio de Janeiro and its hinterland, 1790-1822. University of Virginia, P.H.D, 1986. 
Silveira, P. G.

DIAS, L.C. Les Origines du Réseau Brésilien de Villes. Réseaux d'information et Réseau Urbain au Brésil. Paris: L'Harmattan, 1995. p. 17-42.

FLORENTINO, M. Em Costas Negras: uma história do tráfico de escravos entre a África e o Rio de Janeiro, séculos XVIII e XIX. São Paulo: Companhia das Letras, 2010.

FRAGOSO, J.L. Homens de Grossa Aventura- acumulação e hierarquia na praça mercantil do Rio de Janeiro (1790-1830). Rio de Janeiro: Civilização Brasileira, 1998.

FRANÇA, J.M.C. Outras Visões do Rio de Janeiro Colonial (1582-1808). Rio de Janeiro: José Olympio, 2000.

FURTADO, C. Formação Econômica do Brasil. São Paulo: Editora Nacional, [1959] 1989.

GALVÃO, M.C.C. Características da Geografia dos Transportes no Brasil. In: GALVÃO, M.C.C. Percursos Geográficos. Rio de Janeiro: Lamparina, PGG/UFRJ, [1966] 2009. p. 19-47.

JOHNSON, E.A.J. The Organization of Space in Developing Countries. Cambridge: Harvard University Press, 1970.

LENHARO, A. As Tropas da Moderação. Rio de Janeiro: Secretaria Municipal de Cultura, Turismo e Esportes- Biblioteca Carioca, 1979.

MARCONDES, R.L. Formação da Rede Regional de Abastecimento do Rio de Janeiro: a presença dos negociantes de gado (1801-1811). Revista TOPOI, março, 2001. p. 41-71.

MAURO, F. Os Espaços Marítimos e a Economia Colonial Brasileira. Do Brasil à América. São Paulo: Editora Perspectiva, 1966. p. 77-85.

MORAES, A.C.R. O Sertão: um “outro" geográfico. Terra Brasilis, n4-5, 2002. p. 11-23.

PIRES DO RIO, G.A. Território, Instituições e Superfícies de Regulação. In: BICALHO, A.M.S; GOMES, P.C.C. (Orgs.). Questões Metodológicas e Novas Temáticas na Pesquisa Geográfica. Rio de Janeiro: Publit, 2009. p. 27-44.

PRADO JUNIOR, C. História Econômica do Brasil. São Paulo: Brasiliense, [1945] 1978.

PUMAIN, D.; SAINT-JULIEN, T. Analyse Spatiale- les interactions. Paris: Armand Colin, 2010.

QUINTIERE, L. Principais Antigos Caminhos Fluminenses para as Minas Gerais. Rio de Janeiro: Imprensa Estadual, 1951. 
A Metrópole é Aqui: redes de abastecimento e o porto do Rio de Janeiro no século XIX

RAFFESTIN, C. Por uma Geografia das Redes. Tradução: Maria Cecília França. São Paulo: Editora Ática, 1980.

REVISTA DO INSTITUTO HISTÓRICO E GEOGRÁFICO BRASILEIRO (RIHGB)- 1965, jan/mar, vol. 266, p.227-229; p.298-301.

SANTOS, C. M. O Rio de Janeiro e a Conjuntura Atlântica. Rio de Janeiro: Expressão e Cultura, 1993.

SANTOS, M. A Natureza do Espaço: técnica e tempo, razão e emoção. São Paulo: EDUSP, $4^{\circ}$ edição, ([1996] 2006).

STRAFORINI, R. Tramas que Brilham. Tese de Doutorado - Programa de Pós Graduação em Geografia, 2007, Universidade Federal do Rio de Janeiro (PPGG/UFRJ).

Recebido em: 13/07/2012

Aceito em: 28/12/2012

\footnotetext{
1A perspectiva sincrônica é entendida como o "eixo das coexistências". Nesse caso um tempo particular é selecionado, pode ser um ano ou um século. A diacrônica é vista como o "eixo das sucessões". Nessa perspectiva são isoladas as relações espaciais de fenômenos particulares. A análise sincrônico-diacrônica permite uma análise comparativa entre o recorte temporal adotado e sua influência sobre o fenômeno analisado. Ver a propósito: Estaville Jr. R. (1991). Organizing Time in Historical Geography. In: BROOKS GREEN. D. (Ed.). Historical geography: a methodological portrayal. Savage, Maryland: Rowman and Littlfield Publishers, Ltd., p. 310-324.
} 
